\title{
Disruption of Latent Inhibition in Rats with Postnatal Hippocampal Lesions
}

\author{
G. Grecksch, M.D., H. G. Bernstein, Ph.D., A. Becker, Ph.D., V. Höllt, M.D., and B. Bogerts, M.D.
}

Disruption of latent inhibition has been proposed as a possible model of cognitive abnormalities that underlie positive symptoms of a schizophrenia. We tested neonatal hippocampal lesioned rats in a latent inhibition paradigm. Lesions of the ventral hippocampus were induced by bilateral injections of ibotenic acid in 7 days old rats. The behavior of lesioned rats was tested postpubertally. We found a hyperresponsiveness to dopaminergic stimulation by apomorphine in locomotion tests. Latent inhibition was tested using the acquisition of a conditioned reaction in a two-way shuttle box. Sham operated control animals showed after preexposure of the to-be-conditioned stimulus (combined tone and light stimulus) a low acquisition. Ibotenic acid lesioned animals learned the conditioned reaction with and without preexposure in the same way, indicating disturbed latent inhibition. These results demonstrate disturbances in early postnatal hippocampal lesioned rats comparable with those seen in schizophrenic patients, thus further validating this procedure as a useful animal model of some aspects of schizophrenia.

[Neuropsychopharmacology 20:525-532, 1999]

(C) 1999 American College of Neuropsychopharmacology. Published by Elsevier Science Inc.
KEY WORDS: Schizophrenia; Rat; Postnatal hippocampal lesion; Ibotenic acid; Latent inhibition; Shuttle box

Various animal models have been used to study pathophysiological and pharmacological aspects of schizophrenia. With regard to the etiology and pathophysiology of this disease, several authors proposed that neurodevelopmental abnormalities in limbic key structures of the medial temporal lobe might play a crucial role and that some clinical aspects can be explained by an early acquired limbic dysfunction (for review see Bogerts 1997). Recently, a novel animal model simulating neurodevelopmental lesions in the limbic system was introduced by Lipska et al. (1993). It is based on postnatal lesion of the hippocampus of rats induced by infusion of the excitotoxin ibotenic acid, which produced a

From the Institute of Pharmacology and Toxicology, Department of Psychiatry, Otto-von-Guericke University, Magdeburg, Germany.

Address correspondence to: Dr. G. Grecksch, Otto-von-GuerickeUniversity, Medical Faculty, Institute of Pharmacology and Toxicology, Leipziger Str. 44, D-39120 Magdeburg, Germany.

Received April 2, 1998; revised June 3, 1998; accepted July 17, 1998 temporary specific pattern of alterations in a number of dopamine-related behavioral paradigms (Lipska et al. 1995; Lipska and Weinberger 1995, 1996; Weinberger and Lipska 1995). Comparable results were found by others (Black et al. 1996; Flores et al. 1996; Wan et al. 1996; Wan and Corbett 1997).

Cognitive impairment is a central manifestation of the schizophrenic illness (Kraepelin 1919). Adult patients with schizophrenia also suffer from abnormalities in attention and information processing. Hemsley (1996) proposed a breakdown in the normal relationship between stored material and current sensory input. One type of behavioral process that has been examined in this context with special interest is latent inhibition. Latent inhibition (LI) refers to retarded conditioning to a stimulus that has repeatedly been presented without reinforcement (Lubow 1973; Weiner 1990). This phenomenon is believed to reflect learning to ignore irrelevant stimuli. Disruption of latent inhibition has received increasing attention as a viable animal model of the failure of schizophrenics to ignore irrelevant stimuli (Feldon and Weiner 1991). This disruption 
has been demonstrated in schizophrenia (Lubow et al. 1987; Baruch et al. 1988; Gray et al. 1992, 1995a; Lipp et al. 1992). There also have been negative reports of latent inhibition deficiency (Swerdlow et al. 1996). At present, it is not univocally discussed whether the stage, the duration of illness, or the treatment by neuroleptics could be responsible for these discrepancies. Latent inhibition is similar in humans and animals and can be viewed as reflecting the operation of analogous processes across species (Lubow and Gewirtz 1995).

The present study was undertaken with the intention to test whether the latent inhibition is disrupted in postnatal lesioned rats. First, we tested such rats for behavioral stimulation by the dopaminergic agonist apomorphine. After demonstrating the hyperresponsiveness of lesioned animals to direct dopaminergic stimulation, we tested the performance of lesioned rats in a latent inhibition paradigm. We used the acquisition of a conditioned reaction in a two-way shuttle box with and without pre-exposure to the to-be-conditioned stimulus.

\section{METHODS}

For all procedures followed, ethical approval was sought before the experiments according to the requirements of the National Act on the Use of Experimental Animals (Germany).

\section{Animals}

The experiments were performed on Sprague Dawley rats [Shoe:SPRD, Tierzucht Schönwalde $\mathrm{GmbH}$ ]. The animals were kept under controlled laboratory conditions (light regime of $12 \mathrm{~h}$ light $12 \mathrm{~h}$ dark, temperature $20 \pm 2^{\circ} \mathrm{C}$, air humidity $55-60 \%$ ). They had free access to commercial rat pellets (Altromin 1326) and tap water. The parent animals were housed in macrolon IV cages in permanent breeding. Litters of six to eight pups were formed. Different groups of animals were used for testing at the ages of 6 and $8 \mathrm{wk}$, respectively.

\section{Hippocampal Lesioning}

On day 7, of age pups of a litter were anesthetized by hypothermia, induced by placing on ice for about 15 $\mathrm{min}$. The rats were stabilized in a modified stereotaxic apparatus. An incision was made in the skin overlying the skull and $0.3 \mu \mathrm{l}$ ibotenic acid (Sigma, $15 \mu \mathrm{g} / \mu \mathrm{l}$ ), or physiologic saline was infused bilaterally into the ventral hippocampus at a rate of $0.15 \mu \mathrm{l} / \mathrm{min}$ at $\mathrm{AP}, 2.8$ $\mathrm{mm}$; ML, $3.5 \mathrm{~mm}$; and VD, $5.0 \mathrm{~mm}$ relative to bregma. The injector was withdrawn $3 \mathrm{~min}$ after completion of the infusion. The pups were placed under a warming lamp and then returned to their parents. Rats were weaned 2 weeks postoperatively (PD21). Then 5 ani- mals (lesioned or controls) housed together in a cage under identical conditions.

\section{Behavioral Testing}

For each behavioral test, different groups of animals were used.

\section{Latent Inhibition}

The acquisition and retention of a conditioned reaction in a two-way shuttle box was tested with and without pre-exposure to the to-be-conditioned stimulus using 9-week-old rats.

The automatic shuttle box (TSE, Bad Homburg) was divided into two compartments $(0.25 \times 0.25 \times 0.6 \mathrm{~m})$ separated by a $5-\mathrm{cm}$ hurdle. The conditioned stimuli were light ( $40 \mathrm{~W}$ bulbs located on the central ceiling of each compartment) and a sound produced by a buzzer. The unconditioned stimulus was an electric foot shock of 0.4-0.8 $\mathrm{mA}$ (depending on the individual sensitivity of the animals according to vocalization to minimize stress effects), delivered through stainless steel rods covering the floor.

Pre-Exposure. The animals were placed in the apparatus, and the combination of light and sound was delivered 60 times for $7 \mathrm{~s}$ ( $23 \mathrm{~s}$ interval). Control animals remained for the same duration $(30 \mathrm{~min})$ in the dark chamber.

Training Session. The training session consisting of 80 trials was started immediately after pre-exposure. The animals have to learn, after application of the conditioned stimuli, to move to the other compartment of the shuttle box to avoid the unconditioned stimulus. The conditioned stimuli-unconditioned stimulus interval was $4 \mathrm{~s}$. The stimuli were switched off when the rat had moved to the goal compartment. One trial was limited to $20 \mathrm{~s}$ if the animal failed to react within this period.

Retention Test. Twenty four $\mathrm{h}$ after training session the retention was tested in a relearning test, carried out in the same manner as the training session, but without pre-exposure.

Training and Relearning. The numbers of escapes (reaction time $>4<20 \mathrm{~s}$ ) and conditioned reactions (reaction time $<4 \mathrm{~s}$ ) in training and relearning session were recorded for evaluation of learning performance and memory.

\section{Locomotor Activity}

Five (PD42) or 7 weeks (PD56) after neonatal lesion, the locomotor activity of sham-operated and ibotenic acid lesioned rats was tested in a fully computerized activity 
meter (Moti Test, TSE, Bad Homburg). Different groups of animals were used for the two tests at different ages. Registration of motor activity during a habituation period on the activity meter for $20 \mathrm{~min}$. After habituation the animals were injected with 0.7 or $1.5 \mathrm{mg} / \mathrm{kg}$ apomorphine (Teclapharm $\mathrm{GmbH}$, Lüneburg) i.p., and the locomotion was registered for further $40 \mathrm{~min}$. Different parameters, such as activity time (s) and distance traveled $(\mathrm{m})$ were calculated at intervals of $10 \mathrm{~min}$.

\section{Histology}

After completion of the behavioral experiments, the animals were killed by decapitation. The brains were quickly removed from the cranium, fixed in $10 \%$ formalin and embedded in paraffin. The specimens were cut into $6-\mu \mathrm{m}$ thick coronal sections using a microtome. Every tenth section was Nissl-stained and subjected to morphological inspection under a light microscope (Leitz). For neuroanatomical orientation, the atlas of Paxinos and Watson (1982) was used. The effect of ibotenic acidinduced hippocampal lesions was checked. According to Lipska and Weinberger (1995) the administration of the excitotoxin was regarded as successful if the ventral portion of the hippocampus was bilaterally destroyed without having affected the dorsal part.

\section{Statistics}

To evaluate the stimulating effect of apomorphine on locomotor activity a two way ANOVA with lesion as an independent variable and time interval as a repeated measure using ranks was performed followed by posthoc two-tailed Mann-Whitney U test. Concerning the learning experiment, two-way analysis of variance with lesion and condition (pre-exposure or no pre-exposure) as independent factors was applied, followed by oneway analysis of variance. The basis of statistical decision was a significance level of 0.05 . The calculations were carried out by means of SPSS/PC+software (ANOVA).

\section{RESULTS}

Learning experiments in the shuttle box demonstrated significant differences between the four experimental groups (Figure 1). No significant alteration of the ability of lesioned animals to acquire the conditioned reaction was found under control conditions compared to saline injected rats. The saline groups showed a remarkable latent inhibition, i.e., pre-exposed animals performed significantly fewer conditioned reactions in the training session. The latent inhibition was disrupted in the ibotenic acid lesioned animals. Pre-exposed lesioned
Training

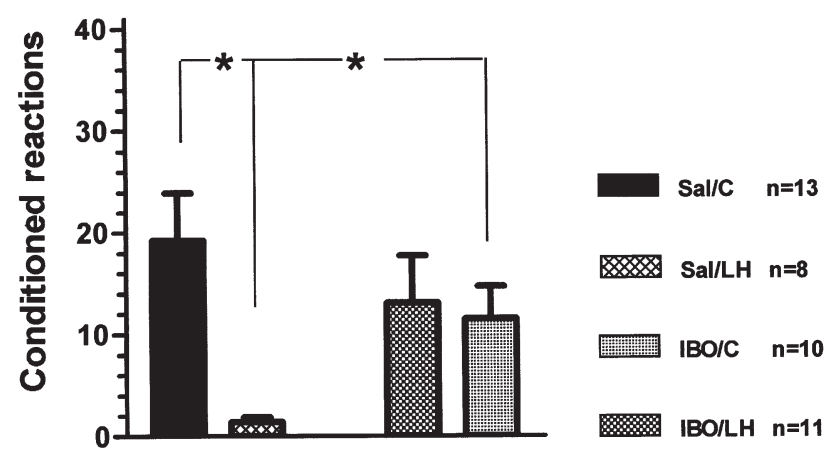

Relearning

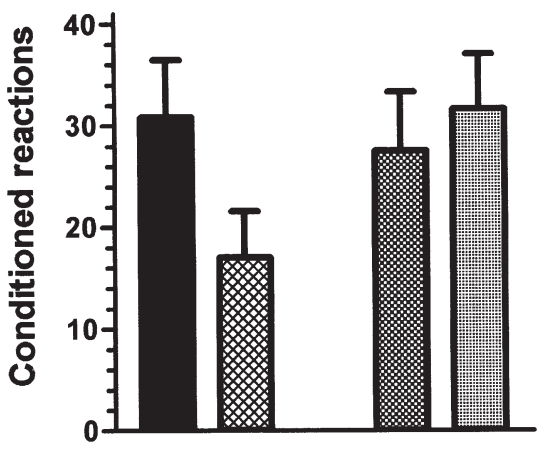

Figure 1. Shuttle box learning with and without preexposure to the to-be-conditioned stimuli. Ordinate, number of conditioned reactions in a session of 60 trials (Mean \pm SEM); $\mathrm{Sal} / \mathrm{C}$, sham-operated animals, 60-min habituation in the dark shuttle box before training; Sal/LH, sham-operated animals, pre-exposure 60 times to the to-be-conditioned stimuli before training; IBO/C, ibotenic acid lesioned animals, 60-min habituation in the dark shuttle box before training; and $\mathrm{IBO} / \mathrm{LH}$, ibotenic acid lesioned animals, preexposure 60 times to the to-be-conditioned stimuli before training. Top: Training session. Analysis of variance, two way: main effects: $\mathrm{F}_{2,40}=2.79, p=.07$; treatment (lesion or not): $\mathrm{F}_{1,22}=0.24, p=.62$; condition (pre-exposure or not): $\mathrm{F}_{1,20}=5.57, p=.02 ; 2$-way interactions (treatment $\times$ condition): $\mathrm{F}_{1,41}=3.93, p=.05$; and explained: $\mathrm{F}_{3,39}=3.08, p=.04$. Analysis of variance, one way: Sal/C vers Sal/LH: $\mathrm{F}_{1,20}=8.70$ $p=.008 ; \mathrm{IBO} / \mathrm{C}$ vers $\mathrm{IBO} / \mathrm{LH}: \mathrm{F}_{1,20}=0.078 p=.78 ; \mathrm{Sal} / \mathrm{C}$ vers IBO/C: $\mathrm{F}_{1,22}=0.83 p=.37$; and Sal/LH vers IBO/LH: $\mathrm{F}_{1,18}=$ $6.98 p=.017$. Bottom: Relearning session. Analysis of variance, two way: main effects: $\mathrm{F}_{2,40}=2.79, p=.53$; treatment (lesion or not): $\mathrm{F}_{1,22}=0.86, p=.35$; condition (pre-exposure or not): $\mathrm{F}_{1,20}=0.60, p=.44 ;$ 2-way interactions (treatment $\times$ condition): $\mathrm{F}_{1,41}=2.80, p=.10$; and explained: $\mathrm{F}_{3,39}=1.26, p=$ 0.30 . Analysis of variance, one way: Sal/C vers Sal/LH: $\mathrm{F}_{1,20}$ $=2.88 p=.10 ; \mathrm{IBO} / \mathrm{C}$ vers IBO $/ \mathrm{LH}: \mathrm{F}_{1,20}=0.42 p=.52 ; \mathrm{Sal} /$ $\mathrm{C}$ vers $\mathrm{IBO} / \mathrm{C}: \mathrm{F}_{1,22}=0.26 p=.61$; and $\mathrm{Sal} / \mathrm{LH}$ vers $\mathrm{IBO} / \mathrm{LH}$ : $\mathrm{F}_{1,18}=3.87 p=.06$. 
rats performed significantly more correct reactions than control animals under the same conditions. Regarding the learning performance in the retention test $24 \mathrm{~h}$ later, no significant differences between the four animal groups investigated were found.

No differences in the locomotor activity on the activity meter were found in the habituation period between neonatal ibotenic acid lesioned rats and control animals in 6- and 8-week-old rats, respectively (Table 1). The activity (activity time in $\mathrm{s}$, distance traveled in $\mathrm{m}$ ) was also identical in both groups after administration of 0.7 $\mathrm{mg} / \mathrm{kg}$ apomorphine i.p. in male 6-week-old rats (Figure 2). When the stimulation by $0.7 \mathrm{mg} / \mathrm{kg}$ IP of the dopaminergic agonist apomorphine was investigated in male 8-week-old rats, a significantly enhanced activation was seen in postnatal lesioned rats compared to control animals (Figure 3). Injection of the relatively high dose of $1.5 \mathrm{mg} / \mathrm{kg}$ apomorphine IP evoked in 8-week-old male control and lesioned rats such a longer lasting activation that a stronger activation in lesioned rats was first seen only in the observation interval 30 to $40 \mathrm{~min}$ after apomorphine injection (Figure 4). We did not observe strong stereotypic responses such as licking, or biting, at this dose of apomorphine.

Histological investigations demonstrated bilateral destruction of the ventral hippocampus. Morphological control revealed that the utmost caudal portion of the hippocampus remained intact in our experiments. A typical lesion pattern is shown in Figure 5. Animals with (1) an incomplete, bilateral destruction of the ventral hippocampus, (2) a unilaterally destroyed ventral hippocampus, or (3) lesions in the dorsal part of the structure were excluded from further analysis of the data of the behavioral experiments. The hippocampus was morphologically intact in rats that had been subjected to saline administration.

Table 1. Activity Times (in s) and Traveled Distances (Meters) During the Habituation Period of $20 \mathrm{~min}$ on the Activity Meter of 6- and 8-wk-old Male Rats

\begin{tabular}{lcc}
\hline Rats & $\begin{array}{c}\text { Activity Time } \\
\mathbf{( s )}\end{array}$ & $\begin{array}{c}\text { Travelled Distance } \\
\mathbf{( m )}\end{array}$ \\
\hline 6-wk-old male & & \\
Sal $n=10$ & $662 \pm 25.5$ & $69.0 \pm 4.15$ \\
IBO $n=19$ & $664 \pm 23.0$ & $67.3 \pm 2.2$ \\
& $\mathrm{U}_{(10,1 ; ; 1)}=68$ & $\mathrm{U}=69.5$ \\
& $z=-0.4$ & $z=-1.1705$ \\
& & $p=.2418$ \\
8-wk-old male & $621 \pm 59$ & $63.2 \pm 8.1$ \\
Sal $n=12$ & $665 \pm 33$ & $67.8 \pm 1.3$ \\
IBO $n=13$ & $\mathrm{U}_{(12,13 ; 1)}=68$ & $\mathrm{U}=27$ \\
& $z=-0.544$ & $z=-1.583$ \\
& $p=.586$ & $p=.114$ \\
\hline
\end{tabular}

Abbreviations: $\mathrm{Sal}=$ sham-lesioned rats; $\mathrm{IBO}=$ ibotenic acid lesioned rats.

\section{$0.7 \mathrm{mg} / \mathrm{kg}$ APO i.p.}
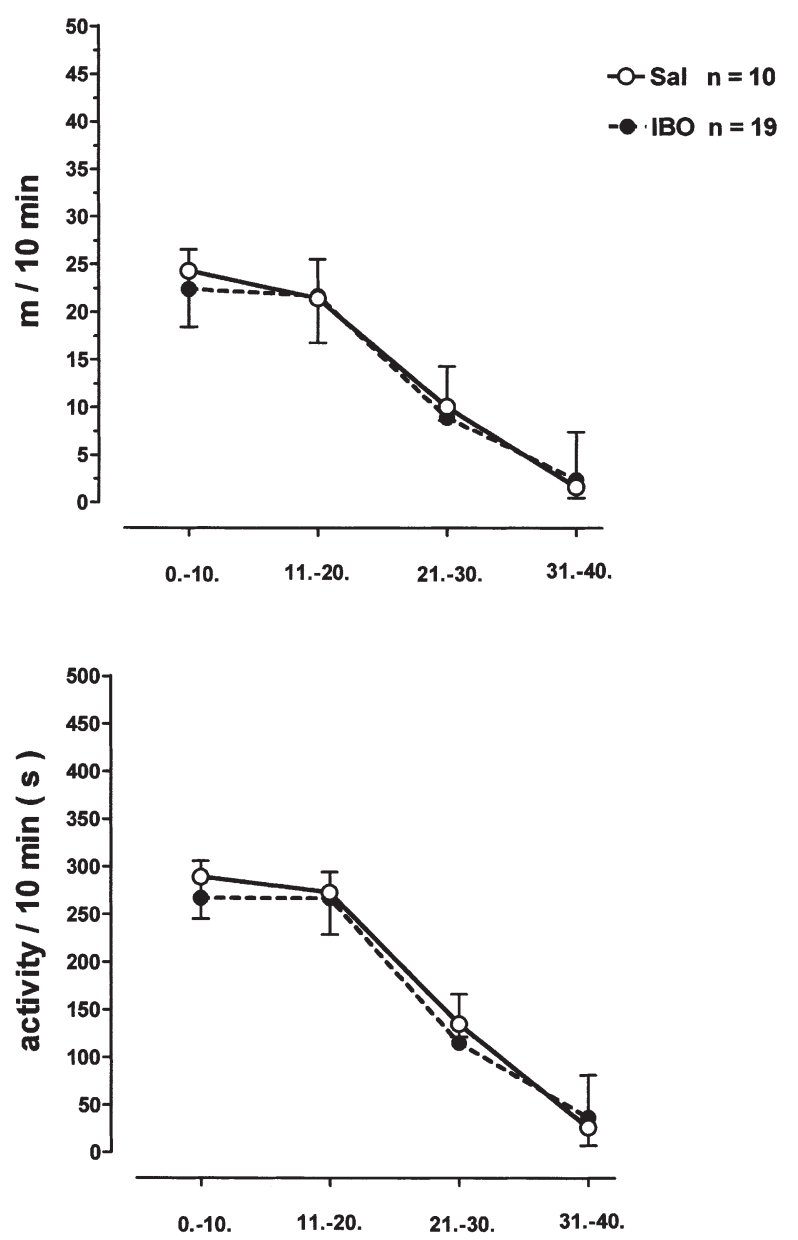

Figure 2. Locomotor activity of 6-wk-old male rats stimulated by $0.7 \mathrm{mg} / \mathrm{kg}$ apomorphine IP in intervals of $10 \mathrm{~min}$ (median \pm standard error of the median). Top: Ordinate (traveled distance in $\mathrm{m} / 10 \mathrm{~min}$ ): $\mathrm{F}_{1,27}=1.2, p=.28 ; 1-10$ min: $\mathrm{U}_{(10,19 ; 1)}=76, z=-0.87, p=.38 ; 11-20 \min : \mathrm{U}_{(10,19 ; 1)}=$ $79, z=-0.73, p=.46 ; 21-30$ min: $U_{(10,19 ; 1)}=65.5, z=-1.35$, $p=.17$; and 31-40 min: $\mathrm{U}_{(10,19 ; 1)}=84, \mathrm{z}=-0.51, p=.61$. Bottom: Abscissa (activity time in $\mathrm{s} / 10 \mathrm{~min}$ ): $\mathrm{F}_{1,27}=0.2, p=.89$; $1-10$ min: $U_{(10,19 ; 1)}=75.5, z=-0.89, p=.37 ; 11-20 \mathrm{~min}:$ $\mathrm{U}_{(10,19 ; 1)}=80, z=-0.69, p=.49 ; 21-30 \mathrm{~min}: \mathrm{U}_{(10,19 ; 1)}=68, z=$ $-1.24, p=.22$; and $31-40 \mathrm{~min}: \mathrm{U}_{(10,19 ; 1)}=84, z=-0.51, p=.61$.

\section{DISCUSSION}

Our results clearly demonstrated a disruption of latent inhibition in postnatal hippocampal lesioned male rats after puberty. Such rats acquire the conditioned reaction in a manner similar to controls. However, after preexposure to the to-be-conditioned stimulus, no latent inhibition was found, whereas the latent inhibition was remarkable in the control group. The fact that only latent inhibition is disrupted, and not memory acquisition and storage of the conditioned reaction, was sup- 


\section{$0.7 \mathrm{mg} / \mathrm{kg}$ APO i.p.}
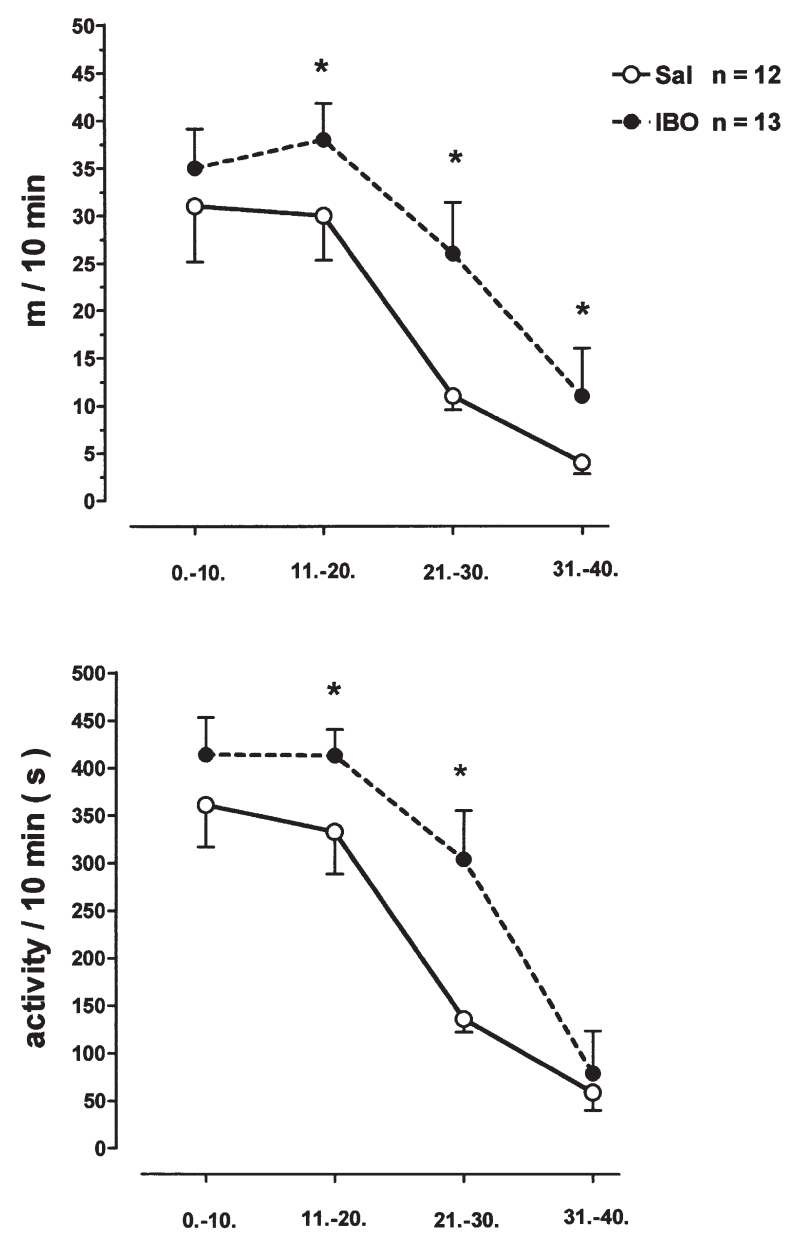

Figure 3. Locomotor activity of 8-wk-old male rats stimulated by $0.7 \mathrm{mg} / \mathrm{kg}$ apomorphine IP in intervals of $10 \mathrm{~min}$ (median \pm standard error of the median). Top: Ordinate (traveled distance in $\mathrm{m} / 10 \mathrm{~min}$ ): $\mathrm{F}_{1,23}=9.65, p=.005 ; 1-10$ min: $\mathrm{U}_{(12,13 ; 1)}=68.5, z=-0.52, p=.61 ; 11-20 \min : \mathrm{U}_{(12,13 ; 1)}=$ $41, z=-2.01, p=.04 ; 21-30 \mathrm{~min}: \mathrm{U}_{(12,13 ; 1)}=24, z=-2.94$, $p=.003$; and 31-40 min: $\mathrm{U}_{(12,13 ; 1)}=41, z=-2.01, p=.04$. Bottom: Ordinate (activity time in $\mathrm{s} / 10 \mathrm{~min}$ ): $\mathrm{F}_{1,23}=9.23, p=$ $.006 ; 1-10$ min: $\mathrm{U}_{(12,13 ; 1)}=63, z=-0.82, p=.42 ; 11-20 \mathrm{~min}$ : $\mathrm{U}_{(12,13 ; 1)}=32.5, z=-2.47, p=.01 ; 21-30 \mathrm{~min}: \mathrm{U}_{(12,13 ; 1)}=29.5$, $z=-2.64, p=.008$; and 31-40 min: $\mathrm{U}_{(12,13 ; 1)}=50, z=-1.52$, $p=.13$.

ported by the retention of lesioned rats being very high in the relearning session $24 \mathrm{~h}$ later. The relevance of disruption in latent inhibition to deficits of schizophrenic patients in information processing and particular to the deficit in the ability to ignore irrelevant stimuli has been extensively documented (Solomon et al. 1981; Weiner et al. 1981). Latent inhibition is disrupted in rats (Solomon et al. 1981; Weiner et al. 1981; Killcross et al. 1994) and in normal humans (Gray et al. 1992) by amphetamine, and this disruption of latent inhibition is antagonized by antipsychotic drugs (Weiner and Feldon 1994; Gos-
$1.5 \mathrm{mg} / \mathrm{kg}$ APO i.p.
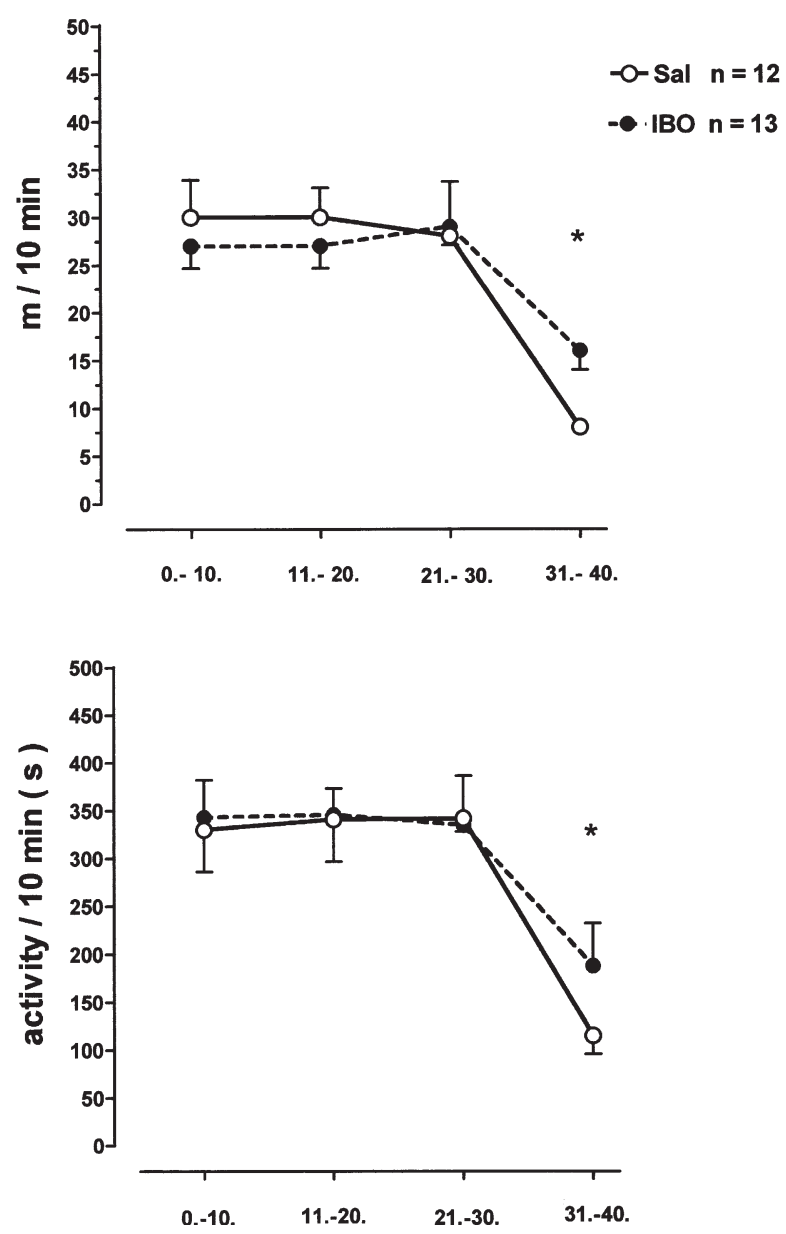

Figure 4. Locomotor activity of 8-wk-old male rats stimulated by $1.5 \mathrm{mg} / \mathrm{kg}$ apomorphine IP in intervals of $10 \mathrm{~min}$ (median \pm standard error of the median). Top: Ordinate (traveled distance in $\mathrm{m} / 10 \mathrm{~min}$ ): $\mathrm{F}_{1,23}=1.23, p=.31 ; 1-10$ min: $\mathrm{U}_{(12,13 ; 1)}=77, z=-0.05, p=.95 ; 11-20 \min : \mathrm{U}_{(12,13 ; 1)}=$ $76, z=-0.11, p=.91 ; 21-30 \min : \mathrm{U}_{(12,13 ; 1)}=76, z=-0.11$, $p=.91$; and 31-40 min: $\mathrm{U}_{(12,13 ; 1)}=43, z=-1.91, p=.05$. Bottom: Ordinate (activity time in $\mathrm{s} / 10 \mathrm{~min}$ ): $\mathrm{F}_{1,23}=0.93, p=$ $.43 ; 1-10 \mathrm{~min}: \mathrm{U}_{(12,13 ; 1)}=72.5, z=-0.29, p=.76 ; 11-20 \mathrm{~min}$ : $\mathrm{U}_{(12,13 ; 1)}=71, z=-0.38, p=.70 ; 21-30 \min : \mathrm{U}_{(12,13 ; 1)}=75.5$, $z=-0.14, p=.89$; and 31-40 min: $\mathrm{U}_{(12,13 ; 1)}=42.5, z=-1.93$, $p=.05$.

selin et al. 1996; Moran et al. 1996). Neuroleptic treatment on its own enhances the latent inhibition effect (Feldon and Weiner 1991; Dunn et al. 1993; Peters and Joseph 1993), in which the model is equally sensitive to typical and atypical antipsychotics (Weiner et al. 1996; Trimble et al. 1997). This enhancement of latent inhibition by neuroleptics is evident in health people, too (Williams et al. 1997). Recently, Lipska et al. (1995) have demonstrated a reduction in prepulse inhibition and an enhancement in the sensitivity to the disruption by apomorphine of prepulse inhibition in neonatal hippocam- 


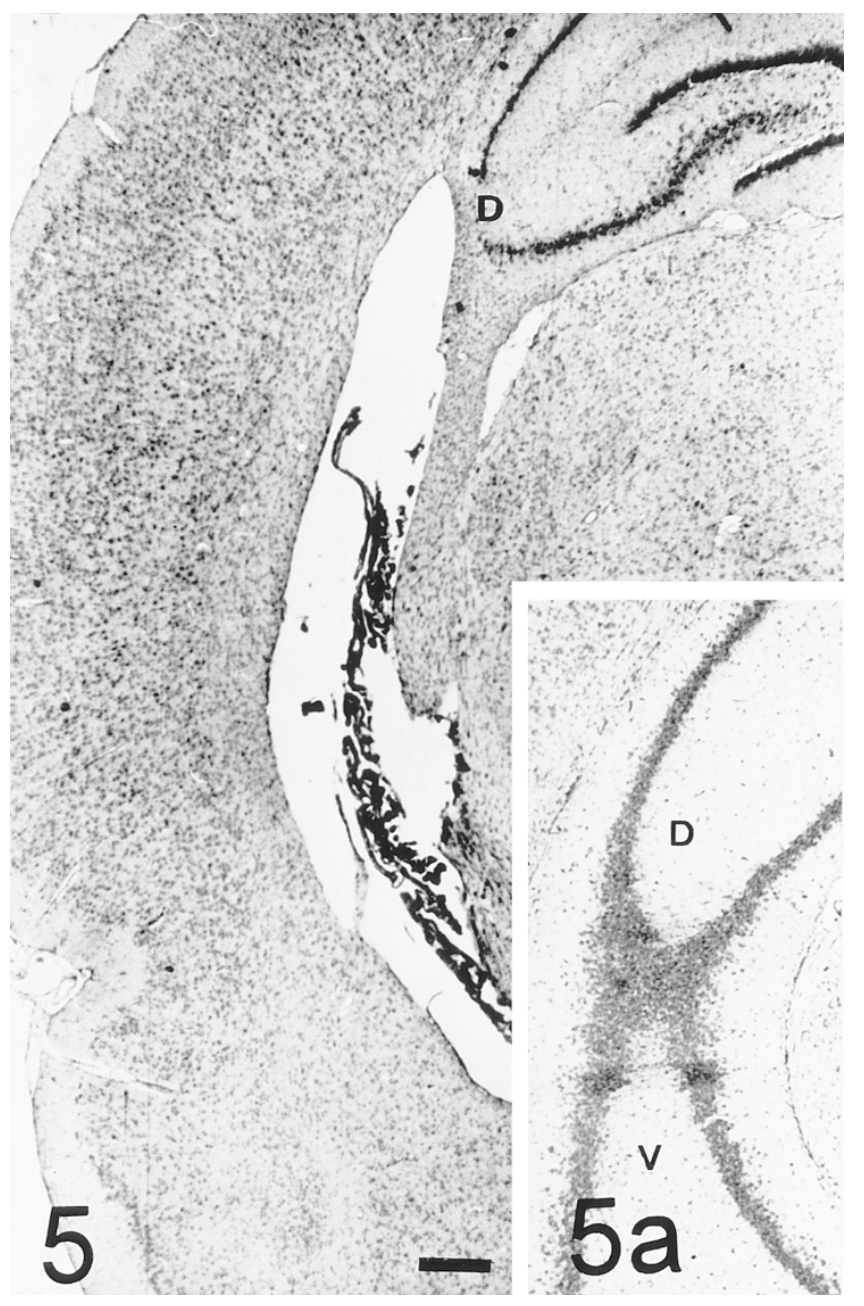

Figure 5. Histological evaluation of the hippocampal lesions induced by ibotenic acid. The ventral hippocampus is destroyed, whereas the dorsal part (D) of the brain structure remains morphologically intact. Bottom right: The inset shows the hippocampal formation of a saline-treated animal (control). Please note that the ventral (V) and the dorsal (D) portions of the hippocampus are morphologically intact. Bar $=95 \mu \mathrm{m}$.

pal-lesioned rats. This reflects a disturbance in sensomotor gating, which is also impaired in adult patients with schizophrenia (Braff et al. 1978; Bolino et al. 1994). It could be suggested that the neuronal basis for the disturbances in prepulse inhibition and in latent inhibition may be similar because both reflect impaired information processing and sensorimotor gating. But studies using local application of dopamine antagonists support the hypothesis that these aspects of information processing are mediated via different neuronal mechanisms (Ellenbroek et al. 1996). The neonatal lesion of the ventral hippocampus in rats leads to disturbances of both behavior pattern and is evident in a similar way in schizophrenics.
There are some reports in the literature demonstrating that latent inhibition depends on the integrity of the hippocampal formation and of the retrohippocampal region (Gray et al. 1995b). Thus, latent inhibition is disrupted by large conventional (electrolytic or aspiration) hippocampal lesions in adult rats (Ackil et al. 1969; Kaye and Pearce 1987a,b; Gray et al. 1991). But an axonsparing excitotoxic lesion limited to the major cellular components of the hippocampus seemed to spare latent inhibition (Honey and Good 1993). It is additionally of special interest in the context of the postnatal lesion model that aspiration lesions of the ventral hippocampus of adult rats did not disrupt the development of latent inhibition (Clark et al. 1992). To validate the specificity of the neurodevelopmental aspect, it is necessary to compare the effects of postnatal lesions of the ventral hippocampus and lesions of the ventral or dorsal hippocampus in adult rats in our latent inhibition paradigm. Thereby, it is important to produce lesions to the same extent.

The intention of initial studies was to demonstrate the hyperresponsiveness to dopaminergic stimulation by the direct dopamine receptor agonist apomorphine in postnatal hippocampal-lesioned male rats when the animals were tested at the age of 8 weeks. The enhanced stimulation compared to sham-lesioned control rats by apomorphine could be shown in different parameters of locomotion and using different doses of apomorphine and was only detectable after puberty. Lesioned rats tested at the age of 6 weeks do not differ from controls. These results are in accordance with the data from the relevant literature, investigating direct and indirect stimulation by apomorphine and amphetamine, respectively (Flores et al. 1996; Lipska et al. 1993; Lipska et al. 1995; Wan et al. 1996; Wan and Corbett 1997). Experiments using different dopaminergic agonists and antagonists (Wan et al. 1996) and microdialysis studies suggest an increased postsynaptic sensitivity of the D2 subtype of receptors as basis for behavioral hyperresponsiveness. As described by Schroeder et al. (unpublished results) D1- and D2-binding sites in the striatum were downregulated in lesioned animals whereas dopamine binding sites in other brain regions were not altered.

These results provide further support for the relatively high degree of construct and face validity of this neurodevelopmental animal model of schizophrenia. Further investigations using typical and atypical neuroleptics should be carried out to test the predictive validity.

\section{REFERENCES}

Ackil J, Mellgren RL, Halgren C, Frommer SP (1969): Effects of CS preexposure on avoidance learning in rats with hippocampal lesions. J Comp Physiol Psychol 69:739-747 
Baruch I, Hemsley DR, Gray JA (1988): Differential performance of acute and chronic schizophrenics in a latent inhibition task. J Nerv Ment Disease 176:598-606

Bogerts B (1997): The temporolimbic system theory of positive schizophrenic symptoms. Schizophr Bull 23:423-435

Bolino F, Di Michele V, Di Cicco L, Manna V, Daneluzzo E, Casacchia M (1994): Sensomotor gating and habituation evoked by electro-cutaneous stimulation in schizophrenia. Biol Psychiatry 36:670-679

Black MD, Hitchcock JM, Sorensen SM (1996): Neonatal hippocampal lesion model of schizophrenia in rats: sex differences and persistence of effects into maturity. Society Neurosci 22:1673

Braff DL, Stone C, Callaway E, Geyer MA, Glick D, Bali L (1978): Prestimulus effects on human startle reflex in normals and schizophrenics. Psychophysiology 15:339-343

Clark AJ, Feldon J, Rawlins JN (1992): Aspiration lesions of rat ventral hippocampus disinhibit responding in conditioned suppression or extinction, but spare latent inhibition and the partial reinforcement extinction effect. Neurosci 48:821-829

Dunn LA, Atwater GE, Kilts CD (1993): Effects of antipsychotic drugs on latent inhibition-sensitivity and specificity of an animal behavioral model of clinical drug action. Psychopharmacology 112:315-323

Ellenbroek BA, Budde S, Cools AR (1996): Prepulse inhibition and latent inhibition: the role of dopamine in the medial prefrontal cortex. Neurosci 75:535-542

Feldon J, Weiner I (1991): The latent inhibition model of schizophrenic attention disorder: haloperidol and sulpirid enhance rats' ability to ignore irrelevant stimuli. Biol Psychiatry 29:635-646

Flores G, Barbeau D, Quirion R, Srivastava LK (1996): Decreased binding of dopamine D3 receptors in the limbic subregions following neonatal bilateral lesion of the hippocampus. J Neurosci 16:2020-2026

Gosselin G, Oberling P, Di Scala G (1996): Antagonism of amphetamine-induced disruption of latent inhibition by the atypical antipsychotic alanzapine in rats. Behav Pharmacol 7:820-826

Gray JA, Feldon J, Rawlins JNP, Hemsley DR, Smith AD (1991): The neuropsychology of schizophrenia. Behav Brain Sci 14:1-20

Gray NS, Hemsley DR, Gray JA (1992): Abolition of latent inhibition in acute, but not chronic, schizophrenics. Neurol Psychiatry Brain Res 1:83-89

Gray NS, Pilowsky LS, Gray JA, Kerwin RW (1995a): Latent inhibition of drug naive schizophrenics: relationship to duration of illness and dopamine D2 binding using SPET. Schizophr Res 17:95-107

Gray JA, Joseph MH, Hemsley DR, Young AMJ, Warburton EC, Boulenguez P, Gregoryan GA, Peters SL, Rawlins JNP, Taib CT, Yee BK, Cassady H, Weiner I, Gal G, Gusak O, Joel D, Shadach E, Shalev U, Tarrasch R, Feldon J (1995b): The role of mesolimbic dopaminergic and retrohippocampal afferents to the nucleus accumbens in latent inhibition: Implications for schizophrenia. Behav Brain Res 71:19-31

Hemsley DR (1996): Schizophrenia-A cognitive model and its implications for the psychological intervention. Behav Modification 20:139-169
Honey RC, Good M (1993): Selective hippocampal lesions abolish the contextual specificity of latent inhibition and conditioning. Behav Neurosci 107:23-33

Kaye H, Pearce JM (1987a): Hippocampal lesions attenuate latent inhibition and the decline of orienting response in rats. Q J Exp Psychol 39B:107-125

Kaye H, Pearce JM (1987b): Hippocampal lesions attenuate latent inhibition of a CS and of a neural stimulus. Psychobiol 15:293-299

Killcross AS, Dickinson A, Robbins TW (1994): Amphetamine-induced disruptions of latent inhibition are reinforcer mediated-implications for animal models of schizophrenic attentional dysfunction. Psychopharmacology 115:185-195

Kraepelin E (1919): Dementia praecox and paraphrenia. New York, Barclay RM.

Lipp OV, Siddle DAT, Vaitl D (1992): Latent inhibition in humans: single-cue conditions revisited. J Exp Psychol Animal Behav Processes 18:115-125

Lipska BK, Weinberger DR (1995): Genetic variation in vulnerability to the behavioral effects of neonatal hippocampal damage in rats. Proc Natl Acad Sci USA 92:8906-8910

Lipska BK, Weinberger DR (1996): Hippocampal damage in the neonatal rat as a model of some aspects of schizophrenia. In Kato N (ed), The hippocampus: Functions and clinical relevance. Amsterdam, Elsevier, pp 465-475

Lipska BK, Jaskiw GE, Weinberger DR (1993): Postpubertal emergency of hyperresponsiveness to stress and amphetamine after neonatal hippocampal damage: A potential animal model of schizophrenia. Neuropsychopharmacology 9:67-75

Lipska BK, Swerdlow NR, Geyer MA, Jaskiw GE, Braff DL, Weinberger DR (1995): Neonatal excitotoxic hippocampal damage in rats causes post-pubertal changes in prepulse inhibition of startle and its disruption by apomorphine. Psychopharmacology 122:35-43

Lubow RE (1973): Latent inhibition. Psychol Bull 79:398-407

Lubow RE, Gewirtz JC (1995): Latent inhibition in humansdata, theory and implication for schizophrenia. Psychol Bull 117:87-108

Lubow RE, Weiner I, Schlossberg A, Baruch I (1987): Latent inhibition and schizophrenia. Bull Psychonom Soc 25:464-467

Moran PM, Fischer TR, Hitchcock, Moser PC (1996): Effects of clozapine on latent inhibition in the rat. Behav Pharmacol 5:120-121

Paxinos G, Watson C (1982): The rat brain in stereotaxic coordinates. Sydney New York London, Academic Press

Peters SL, Joseph MH (1993): Haloperidol potentiation of latent inhibition in rats: evidence for a critical role at conditioning rather than pre-exposure. Behav Pharmacol 4:183-186

Solomon PR, Crider A, Winkelmann JW, Turi A, Kramer RM, Kaplan LJ (1981): Disruption of latent inhibition in the rat chronic amphetamine or haloperidol-induced supersensitivity: Relationship to schizophrenic attention disorder. Biol Psychiatry 16:519-539

Swerdlow NR, Braff DL, Hartston H, Perry W, Geyer MA (1996): Latent inhibition in schizophrenia. Schizophr Res 20:91-103 
Trimble KM, Bell R, King DJ (1997): Enhancement of latent inhibition in the rat by the atypical antipsychotic agent remoxipride. Pharmacol Biochem Behav 56:809-816

Wan RQ, Giovanni A, Kafka SH, Corbett R (1996): Neonatal hippocampal lesions induced hyperresponsiveness to amphetamine: Behavioral and microdialysis studies. Behav Brain Res 78:211-213

Wan RQ, Corbett R (1997): Enhancement of postsynaptic sensitivity to dopaminergic agonists induced by neonatal hippocampal lesions. Neuropsychopharmacology 16:259-268

Weinberger DR, Lipska BK (1995): Cortical maldevelopment, anti-psychotic drugs, and schizophrenia: a search for common ground. Schizophr Res 16:87-110

Weiner I (1990): Neural substrates of latent inhibition: The switching model. Psychol Bull 108:442-461
Weiner I, Feldon J (1994): The latent inhibition model of schizophrenic attention disorder and antipsychotic drug action: Comment on Dunn, Atwater and Kilts (Psychopharmacology, 1993,112, 315-323). Psychopharmacology 116:379-380

Weiner I, Lubow RE, Feldon J (1981): Chronic amphetamine and latent inhibition. Behav Brain Res 2:285-286

Weiner I, Shadach E, Tarrasch R, Kidron R, Feldon J (1996): The latent inhibition model of schizophrenia: further validation using the atypical neuroleptic clozapine. Biol Psychiatry 40:834-843

Williams JH, Wellman NA, Geaney DP, Feldon J, Cowen PJ, Rawlins JNP (1997): Haloperidol enhances latent inhibition in visual tasks in healthy people. Psychopharmacology 133:262-268 